\title{
Therapy-related myelodysplastic syndrome presenting as fulminant heart failure secondary to myeloid sarcoma
}

\author{
Kristina A. Matkowskyj • William R. Wiseman • Jason C. Robin • John P. Norvell • \\ Jyothy Puthumana • Beverly Nelson • LoAnn Peterson • Thomas J. McGarry • \\ Warren G. Tourtellotte
}

Received: 9 July 2009 /Accepted: 13 April 2010/Published online: 5 May 2010

(C) Springer-Verlag 2010

\begin{abstract}
Rapidly progressive heart failure is commonly caused by an extensive myocardial infarction, a mechanical complication of infarction, myocarditis, or acute valvular insufficiency. We present an unusual case that was caused by a diffuse infiltration of the myocardium with leukemic cells (myeloid sarcoma). The patient presented with
\end{abstract}

K. A. Matkowskyj · W. R. Wiseman

Department of Pathology,

Feinberg School of Medicine, Northwestern University,

Ward 3-140, 303 E. Chicago Avenue,

Chicago, IL 60611, USA

J. C. Robin

Department of Medicine,

Feinberg School of Medicine, Northwestern University,

Chicago, IL 60611, USA

\section{J. P. Norvell}

Department of Medicine, Division of Gastroenterology, Feinberg School of Medicine, Northwestern University, Chicago, IL 60611, USA

\section{J. Puthumana $\cdot$ T. J. McGarry}

Department of Medicine, Division of Cardiology,

Feinberg School of Medicine, Northwestern University, Chicago, IL 60611, USA

\section{B. Nelson $\cdot$ L. Peterson}

Department of Pathology, Division of Hematopathology, Feinberg School of Medicine, Northwestern University, Ward 3-140, 303 E. Chicago Avenue,

Chicago, IL 60611, USA

W. G. Tourtellotte $(\bowtie)$

Department of Pathology,

Division of Neuropathology and Department of Neurology,

Feinberg School of Medicine, Northwestern University,

Ward 7-112, 303 E. Chicago Avenue,

Chicago, IL 60611, USA

e-mail: warren@northwestern.edu episodic shortness of breath, he was anemic and thrombocytopenic, and his bone marrow biopsy revealed myelodysplastic syndrome from treatment for oligodendroglioma. His clinical course was characterized by a chronic leak of cardiac enzymes, a new right bundle branch block, and a large pericardial effusion causing tamponade and death from fulminant heart failure and ventricular arrhythmias within 2 weeks. At autopsy, the heart was massively infiltrated with myeloblasts and other immature myeloid cells. There was no evidence of acute leukemia in the bone marrow or peripheral blood. Cardiac infiltration in a patient with myelodysplastic syndrome is extremely rare, especially in the absence of bone marrow involvement by blasts. The recognition of this entity is becoming increasingly important as the incidence of cardiac myeloid sarcoma may be on the rise as the number of patients receiving chemotherapy increases.

Keywords Myeloid sarcoma - Therapy-related myelodysplastic syndrome $\cdot$ Rapidly progressive heart failure $\cdot$ Leukemia cordis

\section{Introduction}

Leukemic cells can infiltrate virtually any organ in the body. A collection of neoplastic, immature myeloid cells found outside the bone marrow is termed an extramedullary myeloid tumor or a myeloid sarcoma $[1,2]$. The tumors can arise during the active phase of acute leukemia, they can be the first manifestation of blastic transformation of chronic leukemia, or they can present as a relapse in patients previously treated for leukemia. Although the underlying disorder is most frequently acute myelogenous leukemia, myeloid sarcoma has also been found in myeloproliferative 
neoplasms and in myelodysplastic syndromes. The most common sites of occurrence are bone, lymph nodes, and skin (leukemia cutis). Cardiac involvement without marrow involvement is extremely rare [3,4]. We describe a patient with fulminant heart failure who was found at autopsy to have diffuse infiltration of the myocardium with leukemic cells. The case was remarkable for the rapidly progressive symptoms, the absence of acute leukemia in the blood and bone marrow, and the fact that the underlying disorder was a chemotherapy-related myelodysplastic syndrome.

\section{Clinical history}

The patient was a 59-year-old male schoolteacher with a history of anaplastic oligodendroglioma diagnosed 3 years before admission. He had been treated by primary resection and chemotherapy with temozolomide, lomustine, and vincristine. The last dose was administered 2 years prior to his current hospitalization. He presented to the emergency department complaining of brief episodes of shortness of breath for 10 days without associated chest pain, fever, edema, or weight loss. Medical history was significant for a postoperative seizure disorder, hypertension, hyperlipidemia, and osteoarthritis. On physical examination, the pulse was 84 beats/min and blood pressure was $150 / 78 \mathrm{~mm} \mathrm{Hg}$. The chest was clear to auscultation, and the cardiac examination showed a regular rhythm and an S4 gallop without a murmur. There was no evidence of lower extremity edema. Laboratory studies revealed a white blood cell count of $6.1 \mathrm{~K} / \mu 1$, a macrocytic anemia (hemoglobin $8.3 \mathrm{~g} / \mathrm{dl}$ ), and thrombocytopenia (platelets $126 \mathrm{~K} / \mu \mathrm{l}$ ). The serum troponin I (TnI) was slightly elevated at $1.2 \mathrm{ng} / \mathrm{ml}$, but the creatine kinase MB (CK-MB) was within normal limits. The brain natriuretic peptide (BNP) level was $443 \mathrm{pg} / \mathrm{ml}$. His electrocardiogram (ECG) showed sinus rhythm and new $\mathrm{T}$-wave inversions in the inferior and lateral leads (Fig. 1a). A transthoracic echocardiogram (TTE) revealed a normal ejection fraction, no wall motion abnormalities, and a small pericardial effusion (Fig. 1b). The patient was diagnosed as having a small non-STsegment elevation myocardial infarction from demand ischemia in the setting of anemia. He was admitted to the coronary care unit, given heparin, and transfused 1 unit of packed red cells.

In working up his anemia, the peripheral blood smear showed mild monocytosis, a prominent basophilia, and a rare dyspoietic neutrophil myelocyte (Fig. 2a). A bone marrow aspirate and biopsy showed $7 \%$ blasts, dysgranulopoiesis, dyserythropoesis, and dysplastic megakaryocytes (Fig. 2b, c). Flow cytometric analysis of the marrow aspirate identified a population of myeloblasts that were partly $\mathrm{CD} 34$ positive and expressed dim CD45 and CD15, positivity for CD13, CD33, myeloperoxidase (MPO) (Fig. 3d-f) and CD11b, and absence of CD3, CD20, and CD117. Cytogenetic studies demonstrated an abnormal mosaic male karyotype (46,XY a
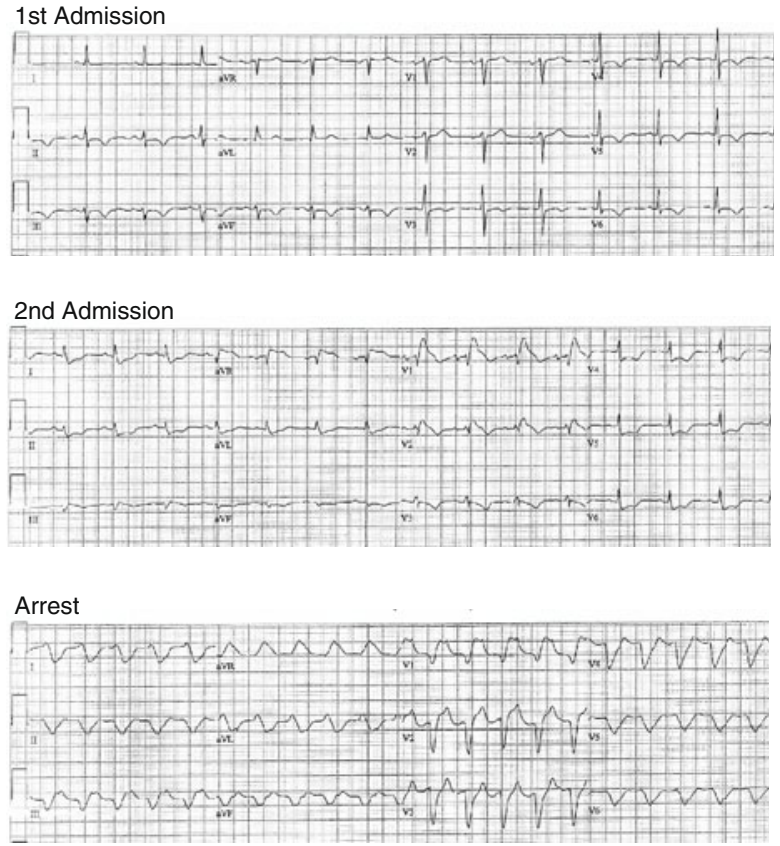

Fig. 1 Echocardiographic still images and electrocardiographic data. a ECG tracings demonstrate the development of a right bundle branch block then VT. b Echocardiographic frames taken during diastole (left) b
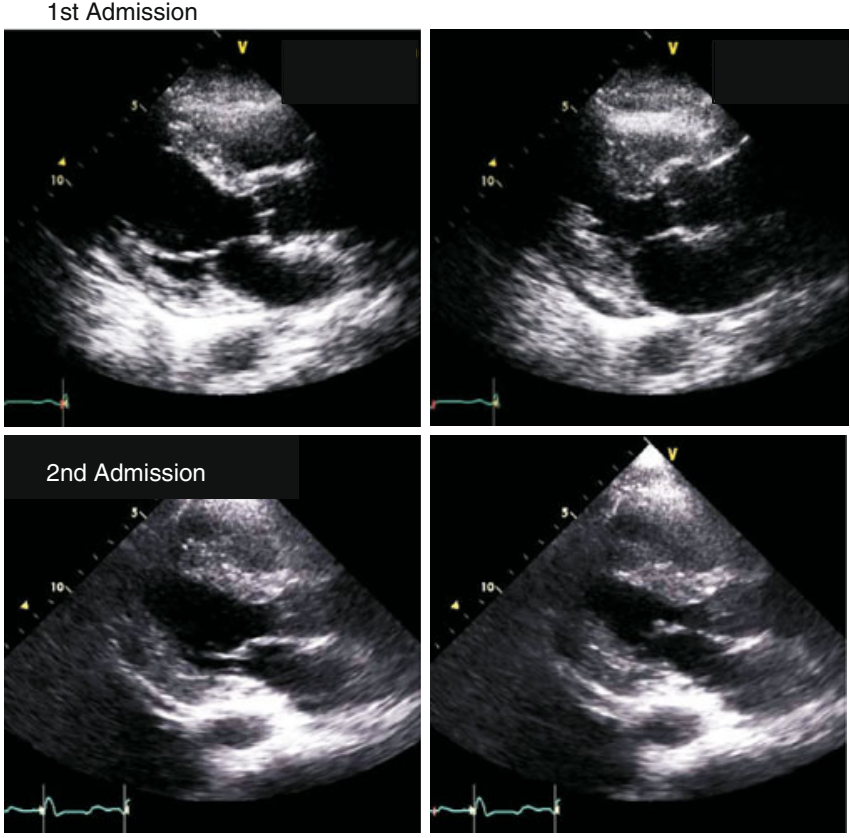

and systole (right) demonstrate deteriorating LV systolic function between the first and second hospital admissions 

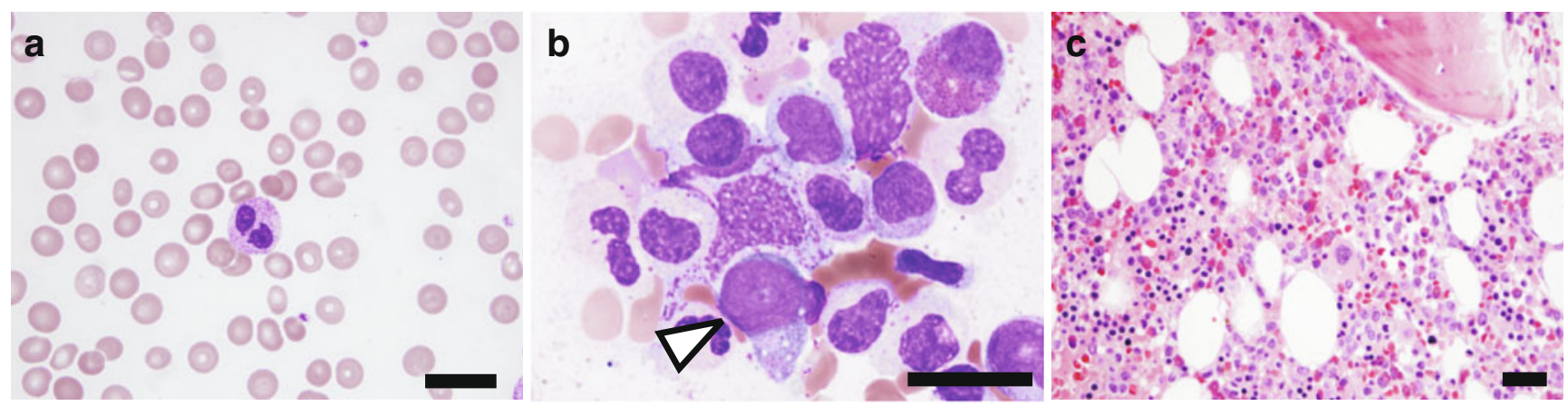

d

e
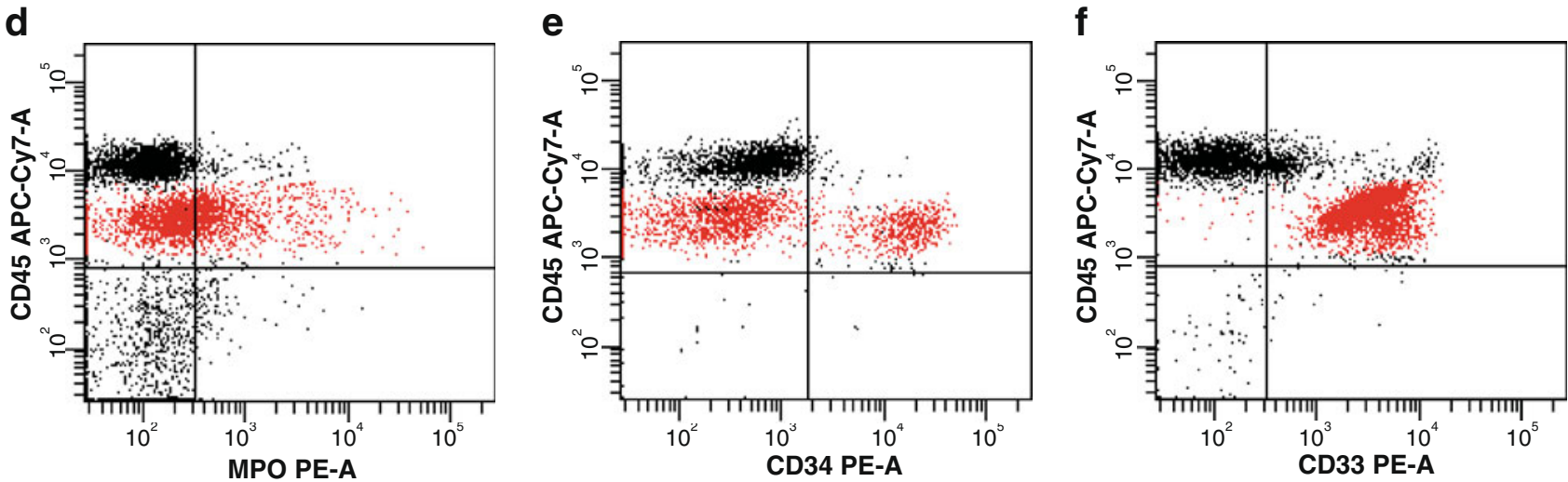

Fig. 2 Hematologic findings. a Peripheral blood smear demonstrating a dyspoietic, hypolobate neutrophil (center). Macrocytic anemia and thrombocytopenia were also present. Bone marrow aspirate (b) illustrating a blast (white arrowhead) with other myeloid precursors, and bone marrow core biopsy (c) illustrating normal bone marrow cells with decreased numbers of mature segmented neutrophils indicating a myeloid shift to immaturity, but no obvious acute

and $45, \mathrm{XY},-7)$. Because of these findings, the patient was diagnosed with therapy-related myelodysplastic syndrome (t-MDS) secondary to previous alkylating-agent chemotherapy. The subtype of MDS was refractory anemia with excess blasts (RAEB). The diagnosis of acute leukemia was excluded because the number of blasts in the bone marrow aspirate and peripheral smear was less than $20 \%$.

Over the next few days, the patient developed increasing fatigue and shortness of breath. There was a gradual rise in his TnI and CK-MB without changes in his ECG (peak TnI $4.41 \mathrm{ng} / \mathrm{ml}$; peak CK-MB $12.9 \mathrm{ng} / \mathrm{ml}$ ). A catheterization of the left side of the heart revealed insignificant coronary artery disease and a mildly elevated left ventricular (LV) end-diastolic pressure (LVEDP) of $15 \mathrm{~mm} \mathrm{Hg}$. He was started on indomethecin for presumed myopericarditis. On the 7th hospital day, a repeat TTE showed a large pericardial effusion with early tamponade (image not shown). Pericardiocentesis was performed, and $600 \mathrm{~mL}$ of serous fluid was drained, with a drop in the pericardial pressure from 15 to $0 \mathrm{~mm} \mathrm{Hg}$. Cytologic examination of the fluid demonstrated 6,000 white blood cells $/ \mathrm{mm}^{3}$ with $36 \%$ basophils, $28 \%$ lymphocytes, $28 \%$ macrophages, $3 \%$ neutrophils, $2 \%$ mono- leukemia. Black size bars for a-c represent $20 \mu \mathrm{m}$. Flow cytometric plots (d-f) illustrating a population of blasts depicted in red. The blasts are dim CD45 positive (d: upper quadrants), partially MPO positive (d: right upper quadrant), partially CD34 positive (e: right upper quadrant), and CD33 positive (f: right upper quadrant) supporting that they are myeloblasts

cytes, and $1 \%$ eosinophils. The patient's symptoms improved after the procedure. The drain was removed, and he was discharged home on the 10th hospital day.

Within 18 hours of discharge, the patient developed acute onset shortness of breath at rest, orthopnea, increasing abdominal girth, and bilateral lower extremity edema. $\mathrm{He}$ returned to the emergency department. On physical examination, his pulse was 98 beats/min and his blood pressure was $127 / 77 \mathrm{~mm} \mathrm{Hg}$. There was jugular venous distention to the angle of the jaw, decreased breath sounds at both lung bases, distant heart sounds, and 4+ pitting edema in the lower extremities. Laboratory tests revealed a TnI of $8.02 \mathrm{ng} / \mathrm{ml}$, CK-MB of $47.0 \mathrm{ng} / \mathrm{ml}$, brain natriuretic peptide (BNP) of $4,438.2 \mathrm{pg} / \mathrm{ml}$, and C-reactive protein of $29.3 \mathrm{mg} / \mathrm{dl}$. His hemoglobin was $9.2 \mathrm{~g} / \mathrm{dl}$, and white blood cell count was $9,200 / \mu \mathrm{L}$. His ECG showed a new right bundle branch block and new ST-segment depression in leads I, II, and V4-V6 (Fig. 1a). Chest x-ray demonstrated cardiomegaly and a left-sided pleural effusion. A TTE revealed a trace pericardial effusion and new global hypokinesis with regional variation in the wall motion. The ejection fraction was $35 \%$, down from $65 \%$ measured 
by TTE 5 days previously (Fig. 1b). The patient was readmitted to the $\mathrm{CCU}$ but developed worsening respiratory distress despite treatment with intravenous diuretics. Intravenous dobutamine was started but stopped because of runs of ventricular tachycardia (VT). About 24 hours after admission, he suffered a cardiac arrest characterized by episodes of sustained VT with intermittent bouts of pulseless electrical activity (PEA; Fig. 1a). Despite successful resuscitation, he quickly developed worsening lactic acidosis with acute renal failure, shock liver, and a coagulopathy that precluded placement of an intra-aortic balloon pump. His blood pressure fell inexorably. After consultation with the patient's wife, supportive measures were withdrawn and he was allowed to expire.

\section{Postmortem examination}

Gross pathological examination showed bibasilar pulmonary congestion ( $R=770 \mathrm{~g}, \mathrm{~L}=610 \mathrm{~g})$ and bilateral serosangineous pleural effusions $(R=570 \mathrm{~mL}, L=1,300 \mathrm{ml})$. There was also portal and splenic vascular congestion. A previous left craniotomy site was identified, and a portion of the left temporal lobe was surgically absent. There was a small serous pericardial effusion $(30 \mathrm{ml})$ with fibrinous exudate. The heart was enlarged (712 g) with LV and septal wall hypertrophy (Fig. 3a). On sectioning, there was mottling of the myocardium throughout its full thickness in both the left and right ventricular walls and in the septum. There was minimal coronary atherosclerosis.

Microscopic examination of the left ventricle, septum, and right ventricle revealed extensive myocyte necrosis. The myocardium was predominantly infiltrated by mediumto large-sized blastic cells with scant cytoplasm (Fig. 3b, c).
There were occasional mature and immature neutrophils and rare eosinophils and megakaryocytes. Immunohistochemical (IHC) studies demonstrated that the blasts stained positively with an antibody for MPO, and no staining was detected against CD3, CD20, CD34, CD45, CD68, CD117, hemoglobin A, and factor VIII (data not shown). These IHC stains were very useful to determine that the infiltrating blasts present in the heart were of myeloid lineage. The CD34 stain on the cardiac tissue was negative by IHC; however, the blasts were only partially positive by flow cytometry performed on the bone marrow. IHC can be less sensitive than flow cytometry since fixation techniques, and processing of the tissue may destroy some of the antigenic epitopes. Taken together with the patient's history of t-MDS, these findings indicate that the patient died of a myeloid sarcoma with blastic transformation involving the heart.

\section{Discussion}

Myeloid sarcoma is a destructive, focal tumor mass composed of immature myeloid cells that most commonly occurs during the active phase of acute myelogenous leukemia. It can also be the first manifestation of blastic transformation in patients with chronic myeloproliferative disorders or myelodysplastic syndrome, or can present as relapse in patients previously treated for leukemia. Although myeloid sarcoma has been reported in almost every site of the body, cardiac involvement is unusual [4, 7, 9-18]. We report the case of a 59-year-old man with a history of t-MDS who died of rapidly progressive heart failure. His LV ejection fraction (LVEF) was decreased from $65 \%$ to $35 \%$ over the course of a few days as documented by serial echocardiograms. At autopsy, the

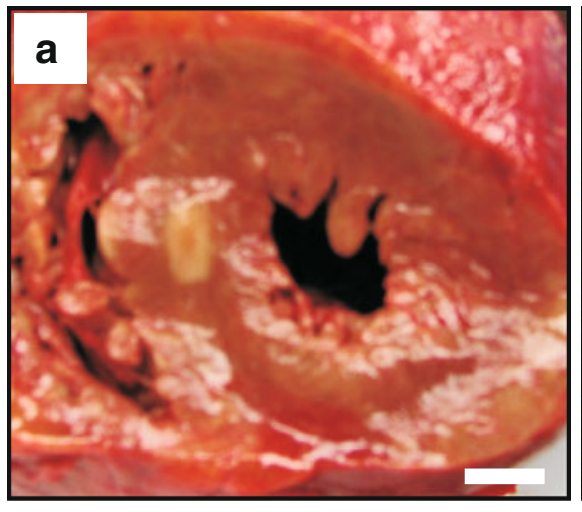

A $-1 \mathrm{~cm}$

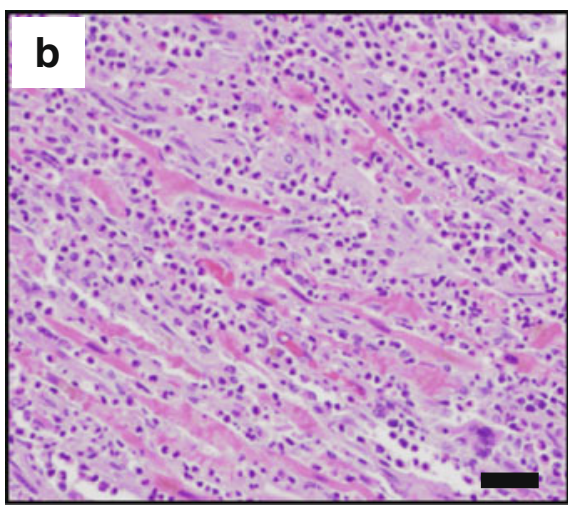

B - 40 um

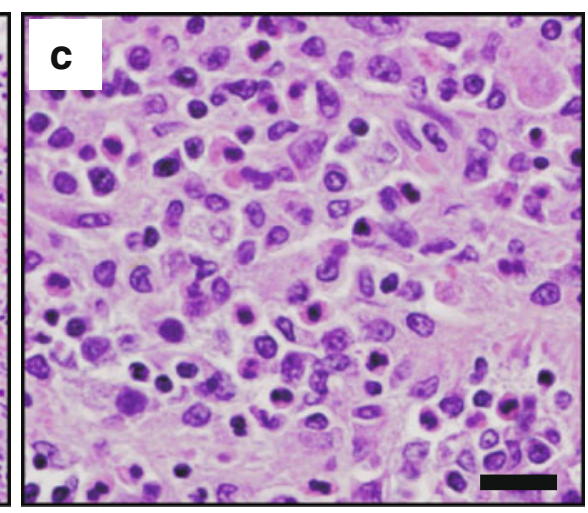

C - 20 um
Fig. 3 Autopsy findings. a Gross specimen of the heart showing circumferential LV hypertrophy and mottling of the myocardium (size bar represents $1 \mathrm{~cm}$ ). b Microscopic view from mottled area demonstrating a mixed inflammatory infiltrate and myocyte necrosis (size bar represents $40 \mu \mathrm{m}$ ). c Higher power view reveals a cellular infiltrate with predominantly medium to large-sized blastic cells with scant cytoplasm and finely dispersed nuclear chromatin, occasional neutrophils, and rare eosinophils (size bar represents $20 \mu \mathrm{m}$ ) 
heart was diffusely infiltrated with myeloblasts and other immature myeloid cells, confirming the diagnosis of myeloid sarcoma. The diagnosis was unexpected given the diagnosis of t-MDS, but no evidence of acute leukemia in the blood or bone marrow and the lack of a distinct cardiac mass on transesophageal echocardiography. The development of cardiac myeloid sarcoma in patients with myelodysplastic syndrome is extremely rare $[5,6,18]$.

The reason for the patient's fulminant course and rapid deterioration in cardiac function is unclear. The patient's continuous elevation of troponin I and CK-MB was too small to account for the deterioration in LV function, and his coronary angiogram showed no significant arterial obstructions. These observations argue against an ischemic etiology. The pericardial effusion did not reaccumulate after it was drained. It is also unlikely that he had developed a restrictive cardiomyopathy given the appearance of his transthoracic echocardiogram, his mildly elevated LV filling pressures, and the rapid pace of the deterioration. It is possible that the leukemic cells physically interfered with cardiac contraction/electrical activity or that they secreted a substance/cytokine that was toxic to the myocytes or decreased their contractility. Near the time of his death, systemic hypotension and a severe metabolic acidosis (arterial $\mathrm{pH}$ 7.00) may have also have contributed to the deterioration in LV function.
Extensive infiltration of the heart by a myeloid sarcoma is distinctly rare (Table 1 ). Although $30 \%-50 \%$ of patients with leukemia are found to have microscopic collections of leukemic cells in the myocardium or endocardium at autopsy, the incidence of gross infiltration is only about $0.7 \%[7,8]$. In many instances, an asymptomatic mass is discovered during routine echocardiography or at autopsy (Table 1). Patients come to clinical attention when the mass obstructs blood flow or compromises valvular function. Typically, the right-sided chambers are affected, and the presenting symptoms are fatigue and pedal edema. In one case, several distinct masses compressed the superior vena cava, pulmonary artery, and aorta causing pulsus paradoxus [9]. Only one case of successful treatment has been reported [4]. In this patient, the tumor caused tricupsid valve stenosis and was treated with radiation and chemotherapy. Eight years later, the tumor recurred. Rarely leukemic infiltration causes complete heart block, which can resolve once the tumor is treated [10]. A similar case in a patient with myelodysplatic syndrome was reported by Mateen et al. [18], with extensive myocardial infiltration by hematopoietic precursors. In our patient, we preferred to use the term myeloid sarcoma since we found leukemic cells diffusely infiltrating the entire heart and markedly effacing the myocardium, despite the lack of a focal, discrete tumor mass.

Table 1 Previous case reports of extramedullary myeloid tumor of the heart

\begin{tabular}{|c|c|c|c|c|c|c|}
\hline Age (y) & Sex & $\begin{array}{l}\text { Hematologic } \\
\text { diagnosis }\end{array}$ & $\begin{array}{l}\text { Previous } \\
\text { chemotherapy }\end{array}$ & Clinical presentation & Cardiac pathology & Reference \\
\hline 48 & M & None & No & $\begin{array}{l}\text { SOB, cough, weakness, } \\
\text { VT, death }\end{array}$ & $\begin{array}{l}\text { Encasement of the SVC, PA, } \\
\text { and aorta }\end{array}$ & Foucar et al. [4] \\
\hline 12 & $\mathrm{~F}$ & APML & Yes & Heart failure, death & Right-sided intracardiac mass & $\begin{array}{l}\text { Jankovic et al. } \\
\text { [11] }\end{array}$ \\
\hline 72 & M & $\begin{array}{l}\text { Agnogenic myeloid } \\
\text { metaplasia }\end{array}$ & ND & RV failure, encasement & $\begin{array}{l}\text { Encasement of the heart and } \\
\text { great vessels }\end{array}$ & $\begin{array}{l}\text { Tillawi and } \\
\text { Variakojis [9] }\end{array}$ \\
\hline 28 & M & Not reported & ND & Dyspnea on exertion & $\begin{array}{l}\text { Masses causing tricuspid and } \\
\text { mitral stenosis }\end{array}$ & $\begin{array}{l}\text { Ichikawa et al. } \\
\text { [12] }\end{array}$ \\
\hline 48 & M & $\begin{array}{l}\text { AML FAB M4 } \\
\text { subtype }\end{array}$ & ND & $\begin{array}{l}\text { Fatigue, positional } \\
\text { dyspnea, headache }\end{array}$ & RA mass & Erdol et al. [13] \\
\hline 34 & M & $\begin{array}{l}\text { AML FAB M1 } \\
\text { subtype }\end{array}$ & Yes & None & Masses in all cardiac chambers & $\begin{array}{l}\text { Makaryus et al. } \\
{[14]}\end{array}$ \\
\hline 39 & M & $\begin{array}{l}\text { AML FAB M1 } \\
\text { subtype }\end{array}$ & Yes & Edema, fatigue, dyspnea & ND & $\begin{array}{l}\text { Marcos-Alberca } \\
\text { et al. [15] }\end{array}$ \\
\hline 28 & & $\begin{array}{l}\text { Acute monoblastic } \\
\text { leukemia }\end{array}$ & ND & Noncardiac (sepsis) & ND & Orts et al. [16] \\
\hline 28 & M & AML FAB M2 & $\begin{array}{l}\text { Stem cell } \\
\text { transplantation }\end{array}$ & Noncardiac and dyspnea & ND & Kara et al. [17] \\
\hline 64 & $\mathrm{~F}$ & MDS (RAEB) & No & Lethargy, weakness, SOB & $\begin{array}{l}\text { Diffuse infiltration of the } \\
\text { myocardium }\end{array}$ & Mateen et al. [18] \\
\hline
\end{tabular}

$R A E B$ refractory anemia with excess blasts, $S O B$ shortness of breath, $V T$ ventricular tachycardia, $P A$ pulmonary artery, $N D$ not documented, $R V$ right ventricle, $A P M L$ acute promyelocytic leukemia, $A M L F A B$ acute myeloid leukemia, French-American-British classification, $R A$ right atrium, $M D S$ myelodysplastic syndrome 
Although cardiac involvement by a myeloid sarcoma is unusual, this case demonstrates the importance of keeping this diagnosis in mind in patients with myelodysplastic syndrome or patients who present with heart failure of uncertain etiology. The incidence of myelodysplastic syndrome is rising as the population ages and as the number of long-term cancer survivors who received aklyating chemotherapy increases. These trends may portend an increase in the number of patients with cardiac myeloid sarcoma.

\section{References}

1. Traweek ST, Arber DA, Rappaport H, Brynes RK (1993) Extramedullary myeloid cell tumors. An immunohistochemical and morphologic study of 28 cases. Am J Surg Pathol 17:1011-1019

2. Quintanilla-Martinez L, Zukerberg LR, Ferry JA, Harris NL (1995) Extramedullary tumors of lymphoid or myeloid blasts. The role of immunohistology in diagnosis and classification. Am J Clin Pathol 104:431-443

3. Comings DE, Fayen AW, Carter P (1965) Myeloblastoma preceeding blood and marrow evidence of acute leukemia. Cancer $18: 253-258$

4. Foucar K, Foucar E, Willman C, Horvath A, Gerety RL (1987) Nonleukemic granulocytic sarcoma of the heart: a report of a fatal case. Am J Hematol 25:325-332

5. Evans C, Rosenfeld CS, Winkelstein A, Shadduck RK, Pataki KI, Oldham FB (1990) Perforation of an unsuspected cecal granulocytic sarcoma during therapy with granulocyte-macrophage colonystimulating factor. N Engl J Med 322:337-338

6. Watanabe M, Sashikata T, Kizaki T, Fujiwara T, Ugai K, Nakagawa T (1990) A case of epidural granulocytic sarcoma preceding acute leukemia. Acta Pathol Jpn 40:922-926

7. Roberts WC, Bodey GP, Wertlake PT (1968) The heart in acute leukemia. A study of 420 autopsy cases. Am J Cardiol 21:388412
8. Liu PI, Ishimaru T, McGregor DH, Okada H, Steer A (1973) Autopsy study of granulocytic sarcoma (chloroma) in patients with myelogenous leukemia, Hiroshima-Nagasaki 1949-1969. Cancer 31:948-955

9. Tillawi IS, Variakojis D (1990) Refractory right ventricular failure due to granulocytic sarcoma. Arch Pathol Lab Med 114:983-985

10. Civelek AC, Brinker JA, Camargo EE, Links JM, Wagner HN (1992) Rest thallium-201 myocardial perfusion imaging in a patient with leukaemic infiltration of the heart. Eur J Nucl Med 19:306-308

11. Jankovic M, Bonacina E, Masera G, Uderzo C, Galli MA, Ottaviani V, Fesslova V, di Massino UV, Figini A, Cattaneo M et al (1987) Cardiac relapses in myeloid leukemia: case report and review of the literature. Pediatr Hematol Oncol 4:237-245

12. Ichikawa K, Ishizuka N, Shimamura K, Tanimoto K, Aoka Y, Nagashima H, Sakomura Y, Koyanagi H, Motoji T, Mizoguchi H, Kasanuki H (2001) Mitral valve stenosis due to primary cardiac granulocytic sarcoma relapsing 8 years after complete remission: a case report. J Cardiol 38:219-224

13. Erdol C, Ovali E, Baykan M (2003) Granulocytic sarcoma presenting as a right atrial mass. Acta Cardiol 58:155-158

14. Makaryus AN, Tung F, Liu W, Mangion J, Kort S (2003) Extensive neoplastic cardiac infiltration in a patient with acute myelogenous leukemia: role of echocardiography. Echocardiography 20:539-544

15. Marcos-Alberca P, Ibanez B, Rey M, Roman A, Rabago R, Orejas M, Tomas JF, Farre J (2004) Cardiac granulocytic sarcoma (chloroma): in vivo diagnosis with transesophageal echocardiography. J Am Soc Echocardiogr 17:1000-1002

16. Orts M, Ribera JM, Calatrava A, Larrouse E, Catalan R, Navarro JT, Milla F, Feliu E (1996) Pseudotumorous cardiac infiltration in a patient with acute monoblastic leukemia. Med Clin (Barc) 106:545-547

17. Kara IO, Sahin B, Paydas S, Kara B (2005) Granulocytic sarcoma of the heart: extramedullary relapse of acute myeloblastic leukemia after allogeneic stem cell transplantation successfully treated by chemotherapy alone. Leuk Lymphoma 46:1081-1084

18. Mateen FJ, Harding SR, Saxena A (2006) Extensive myocardial infiltration by hemopoietic precursors in a patient with myelodysplastic syndrome. BMC Blood Disord 6:4 